\title{
Integrated production planning and control: A multi-objective optimization model
}

\author{
Wang Cheng, ${ }^{1,2}$ Liu Xiao-Bing ${ }^{1}$ \\ ${ }^{1}$ Dalian University of Technology, ${ }^{2}$ Qiqihar University (China) \\ wangcheng_dalian@126.com,sjksy@sina.com
}

Received: March 2013

Accepted: May 2013

\section{Abstract:}

Purpose Production planning and control has crucial impact on the production and business activities of enterprise. Enterprise Resource Planning (ERP) is the most popular resources planning and management system, however there are some shortcomings and deficiencies in the production planning and control because its core component is still the Material Requirements Planning (MRP). For the defects of the ERP system, many improvement and optimization schemes have been proposed, and improve the feasibility and practicality of the plan in some extent, but it is fewer studies considering the whole planning system optimization in the multiple performance management objectives and achieving better application performance. The purpose of this paper is to propose a multi-objective production planning optimization model Based on the point of view of the integration of production planning and control, in order to achieve optimization and control of enterprise manufacturing management.

Design/methodalogy/approadr On the analysis of ERP planning system's defects and disadvantages, and related research and literature, a multi-objective production planning optimization model is proposed, in addition to net demand and capacity, multiple performance management objectives, such as on-time delivery, production balance, inventory, overtime production, are considered incorporating into the examination scope of the model, so that the manufacturing process could be management and controlled Optimally between multiple 
objectives. The validity and practicability of the model will be verified by the instance in the last part of the paper.

Findings: The main finding is that production planning management of manufacturing enterprise considers not only the capacity and materials, but also a variety of performance management objectives in the production process, and building a multi-objective optimization model can effectively optimize the management and control of enterprise manufacturing.

Practical implications: By setting cost parameters for all kinds of production objectives, mangers can maintain the balances among multiple objectives, and achieve the optimized management and control in the manufacturing process.

Originality/value This paper propose a multi-objective production planning optimization model, which can consider multiple performance management objectives of manufacturing process, and can achieve effective planning and control of production process of enterprise.

Keywards: production planning and control, multi-objective optimization, optimization model, ERP

\section{Introduction}

Planning is the primary managerial function for enterprises, which is the direction and instruction to coordinate and cooperate the enterprise's overall operation. Only with powerful planning function, shall the business and production operation go smoothly with the instructions given. Enterprise Resource Planning, which is also known as ERP, is the most popular resource management system at present. ERP, originated as an extension of Material Requirements Planning (MRP) developed in 1960s, is a management and control system with planning as the dominant function, facing overall resources of enterprises, which has become the leading system of production planning arrangements and resource management for many manufacturing enterprises. However, with decades of developments in the management thoughts and philosophies of ERP, the traditional calculation methods of MRP is the implementation foundation for ERP and the planning system as shown in Figure 1 (Liu, Zhou \& Liu, 2001).

There are five tiers in the planning management of ERP, including business planning, sales and operational planning, master production schedule, material demand planning and capacity planning ERP and the contents of which are ranged from macro-prospective to microprospective, from tactical to strategic and from rough to detailed. Every planning centers the basic contradiction between supply and demand and the harmonies among the plans in each tier are achieved through the feedbacks. The major disadvantages existed in this planning 
system are: (1) Lack of overall optimization mechanism. The optimization in the planning system only focuses on the planning in each tier and the harmonies among the plans in each tier depend on the feedback mechanism, which will be done manually, while the overall optimization proposal cannot be given automatically. This is also the most criticized part of ERP (Jia, Liao, Wang \& Shen, 2002). (2) The disconnection between material demand planning and capacity demand planning, which are not considered in the unified framework. Material demand planning is calculated based on the unlimited capacity and fixed production lead time, which cannot assure the feasibility of the calculated capacity result. The result of the material demand planning will be the input of capacity demand planning, so the calculation can only be checked passively, while optimization suggestion will be not given and only manual adjustment can be applied when over loaded. (3) Only material and capacity are put into considerations to determine whether it is reasonable to make the production planning arrangements, but other performance management objectives in the manufacturing process are not brought into the examination scope. In the situation with customers' needs changing rapidly and daily production management getting more and more complicated, the above mentioned disadvantages are getting even more prominent and the conventional ERP planning model cannot adapt the changing needs more and more.

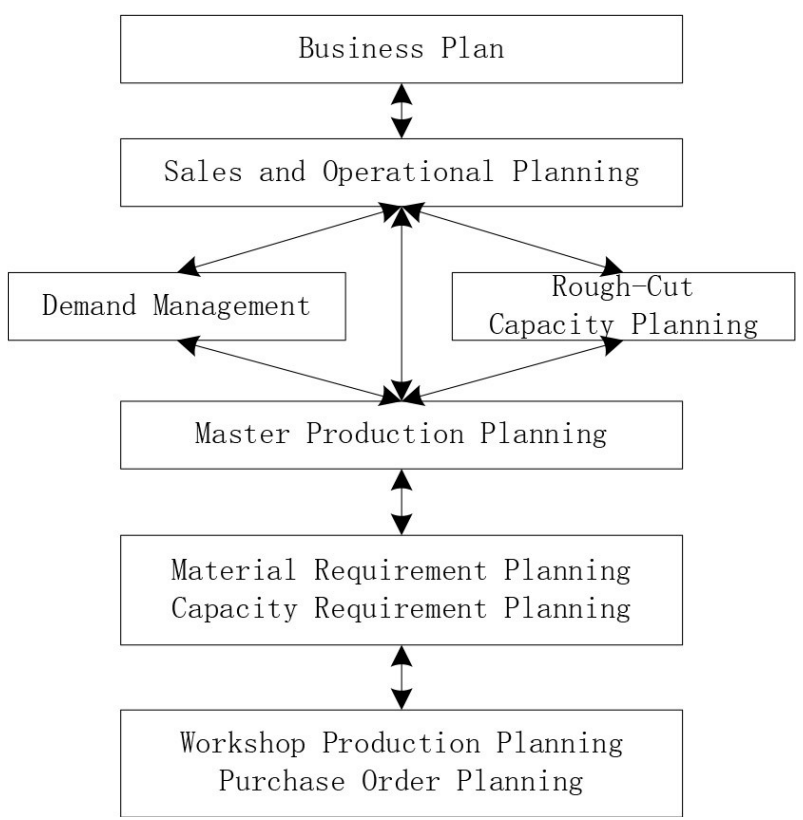

Figure 1. ERP Planning System

In the view of above mentioned problems, academic scholars have done plenty of studies in the production planning and control. These studies mainly include the following 5 aspects: (1) studies in the main production planning, are carried out to increase the practicability, improvements have been done in the choices of multiple objectives, planning model and calculations (Jia et al., 2002; Chen, 2001; Smith, Robles \& Cárdenas-Barrón, 2009). (2) Aiming at the defects of MRP planning methods, studies have been carried out in batch production and lead time (Hao \& Wu, 2005; Jodlbauer \& Reitner, 2012; Cui, Liu \& Yan, 2003) 
to solve the disconnection problem between material demand planning and capacity demand planning. (3) Studies in capacity demand planning, such as improving the working capacity center and balanced methods (Zhuang \& He, 2002) applying different calculation methods to optimize the operational route (Huang, Cai, Hu, Wang \& Ling, 2009; Liu, Wang, Zhou \& Rao, 2010), to cover the shortage of the capacity demand planning. (4) studies in production scheduling mainly focusing on scheduling model (Wang, Liu, Lin \& Zhao, 2012; Pan, Liao \& Xi, 2010), scheduling calculations (Wang, Zhang \& Lu, 2007; Shu \& Wang, 2010) and applications in specific industries (Hao, 2008; Kopanos, Puigjaner \& Georgiadis, 2010; Kopanos, Puigjaner $\&$ Georgiadis, 2011), to provide solutions to the problems of organizing different resources and making effective allocation so that the usability and practicality of production scheduling can be improved. (5) Overall design or optimization for the enterprise planning model. If integrated planning and control methods is adapted to consider planning and control in a unified framework to make planning and control in coordination (Zhang \& Wang, 2008; Xiao, Zhang \& Chang, 2010; Kanet \& Stlein,2010). Build up a model to optimize the enterprise's overall resources to achieve the overall optimization for enterprise's resources (Lan, 2004). In general, most studies have been focusing on the defects and disadvantages of the ERP system to carry out partial improvement or optimization, which increase the usability and practicality in certain level for better execution effects. At the same time, studies on the optimization design of planning system as a whole, which have come to a better execution effect, are relatively less. In view of the complication of the management and scheduling of enterprise's resources, there are still no unified, mature and effective solutions in the production scheduling and control.

In the perspective of integrated production planning and control, this paper proposed a multiobjective production planning optimization model, where in addition to the net production demand requirement and capacity when making production planning, performance objectives in the manufacturing process are also brought into examination scope, so that mangers can choose from multiple objectives to achieve the optimized management and control in the manufacturing process.

\section{Optimization Model of Multi-objective Production Planning}

As mentioned above, the conventional planning systems mostly focus on the customer service level (delivery) to carry out the production planning and control for the objectives (Witkowski, Antchak \& Antchak,2004; Kanet \& Stlein, 2010). However in manufacturing, when there are lack of capacity, over loaded production tasks or accidents, delayed delivery may occur and besides the delivery, performance index shall also be considered, such as occupied inventory level, production equilibrium, overtime production and so on. These factors are interrelated and restricted with each other, which have great impacts on the enterprise's production planning.

The production planning optimization model proposed in this paper has brought the four objectives into examination scope and allow the managers to choose and balance among 
multiple objectives, in order to realize the optimization of multiple objectives. To simplify the problems, the model proposed in this model is based on the following assumptions: (1) products are produced with single resource and the product quantity can represent the capacity; (2) bill of material is single level.

\subsection{Model Overview}

The production optimization model based on multiple objectives is shown as in Figure 2 .

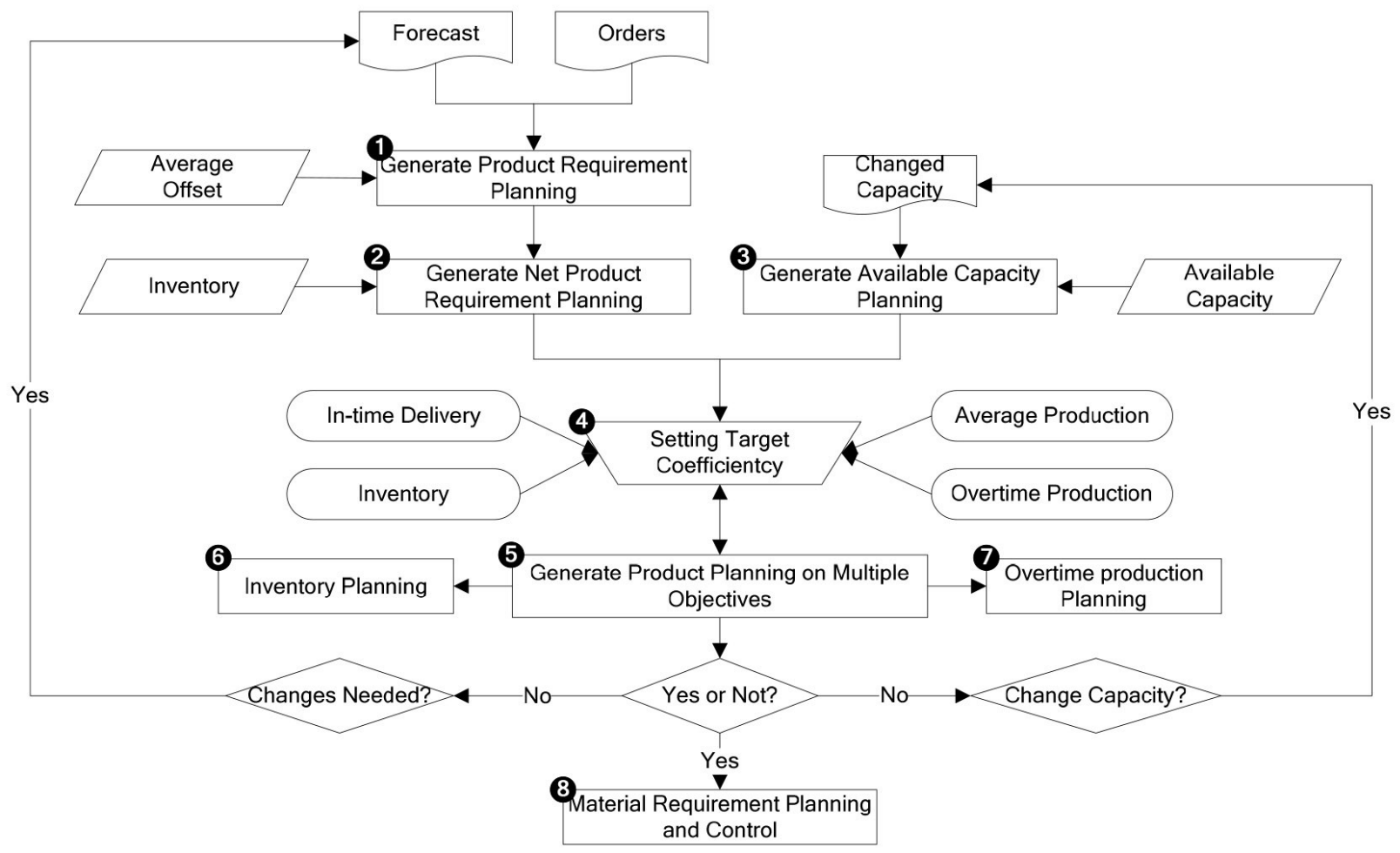

Figure 2. Production Optimization Model based on Multiple Objectives

The basic logics of this model are: based on the forecast and order data, while considering average and offset rules to generate production demand planning, and then based on the current inventory and safety inventory to generate net product demand planning 2 . Current capacity and changed capacity are applied to generate the available capacity planning where available capacity including regular capacity and overtime capacity. Consider the net product demand planning and available capacity planning and combined 4 performance objectives including in time delivery, balanced production, inventory and overtime production to generate multi-objective production planning, inventory planning $\mathbf{6}$ and overtime scheduling $\mathbf{6}$. During this process, it can be executed repeatedly and through changing the objective coefficient, different planning results can be achieved. If there is still no satisfied results after several adjustments, then changing needs or capacity can be considered. If the result is satisfied, then successive material demand planning and control can be carried out $\mathbf{8}$. 
The key problems can be solved by this model:

- explanations to the sources of product needs are given, along with the average and offset rules between forecast and offset rules.

- planning shall meet the capacity demand to assure the capacity feasibility of the production planning.

- production planning is optimized by multiple performance objectives including in time delivery, balanced production, inventory, overtime production, etc., meanwhile the future product inventory planning and overtime production planning are also generated.

- material demand planning is generated by the optimized production planning.

\subsubsection{Product Demand Planning}

Product demand planning is the forecast and arrangements for the product demands in the market for certain time period in the future, the main resources of which are market forecast and received product orders. Market forecast, based on the historic sales data and the future development in the market to come to future market demand for the product applying certain forecasting methods. According to different forecast periods, the product forecast can be divided into annual, seasonal, monthly forecast etc. In order to make the production scheduling more convenient, the data used to do the product forecast should be averaged first in general. Average is an average processing carried out according to detailed time scales, including monthly average, weekly average and daily average.

Another important source for product demand is the received orders which have specified the future delivery time and amount. Compared to the market research, the data in the orders and enterprise shall deliver the products according to the orders' data to increase the customers' satisfaction.

When confirming the product demand, the sources may come from orders, forecast, or both. If considering the orders and forecast at the same time, then there may be some repeat existed, so the repeated parts which may influence the forecast and order shall be deleted. Since the data provided in the orders is reliable and real, generally speaking, methods shall be applied by using orders to offset the forecast. The offset relations between the orders and forecast are as follows:

$\mathrm{GD}_{\mathrm{i}}=\mathrm{F}_{\text {offset rules }}\left(\mathrm{FN}_{\mathrm{i}}, \mathrm{ON}_{\mathrm{i}}\right)$

$\mathrm{GD}_{\mathrm{i}}$ : Product demand in No. $\mathrm{i}$

$\mathrm{FN}_{\mathrm{i}}$ : Product forecast in No. $\mathrm{i}$

$\mathrm{ON}_{\mathrm{i}}$ : Orders in No.i 
Offset Rules:

- Forecast only: Market forecast is put into consideration only, without any consideration of the customers' order, which is applicable for enterprise mainly in mass production and retail business.

- Customers' Orders only: Customers' order is considered only, without market forecast, which is suitable for MTO and ETO enterprises.

- Forecast \& Customer's Orders, with no offsets: Market forecast and customers' orders are both considered, added up simply with no offsets, which is suitable for mixed enterprises.

- Forecast \& Customer's Orders, with reversed offsets: Put market forecast and customers' orders into considerations at the same time and the customers' orders will be offset by previous forecast. If the customers' order is larger than the total previous orders, then the forecast before the order can be all offset and only the order's data can be reserved. If the order is larger than part of the previous forecast, then the order can only offset the certain part of forecast data.

- Forecast \& Customer's Orders, with positive offsets: Put market forecast and customers' orders into considerations at the same time and the customers' orders will be offset by future forecast. If the customers' order is larger than the total future orders, then the forecast after the order can be all offset and only the order's data can be reserved. If the order is larger than part of the future forecast, then the order can only offset the certain part of forecast data.

- Forecast \& Customer's Orders, with reversed offsets first and then by positive offsets: Put market forecast and customers' orders into considerations at the same time and the customers' orders will be offset by previous forecast. If the order can offset the previous forecast data totally, then keep offsetting the future forecast data.

- Forecast \& Customer's Orders, with positive offsets first and then by reversed offsets: Put market forecast and customers' orders into considerations at the same time and the customers' orders will be offset by future forecast. If the order can offset the future forecast data totally, then keep offsetting the previous forecast data.

For example, if the sales is 3000 at the first 10 days of April, and after daily average, the daily sales amount is 300 . Say that received customers' order is 700 due on April 2, then the results of the offset rule between forecast and customer's orders are shown in Table 1. 


\begin{tabular}{|c|c|c|c|c|c|c|c|c|c|c|c|c|}
\hline \multicolumn{2}{|l|}{ Item } & 1 & 2 & 3 & 4 & 5 & 6 & 7 & 8 & 9 & 10 & Total \\
\hline \multicolumn{2}{|c|}{ Forecast (daily average) } & 300 & 300 & 300 & 300 & 300 & 300 & 300 & 300 & 300 & 300 & 3000 \\
\hline \multicolumn{2}{|c|}{ Customer's Orders } & & 700 & & & & & & & & & 700 \\
\hline \multicolumn{2}{|c|}{ Forecast Only } & 300 & 300 & 300 & 300 & 300 & 300 & 300 & 300 & 300 & 300 & 3000 \\
\hline \multicolumn{2}{|c|}{ Orders Only } & & 700 & & & & & & & & & 700 \\
\hline \multirow{5}{*}{$\begin{array}{l}\text { Forecast } \\
+ \\
\text { Orders }\end{array}$} & No Offsets & 300 & 1000 & 300 & 300 & 300 & 300 & 300 & 300 & 300 & 300 & 3700 \\
\hline & Reversed Offsets & & 700 & 300 & 300 & 300 & 300 & 300 & 300 & 300 & 300 & 3100 \\
\hline & Positive Offsets & 300 & 700 & & 200 & 300 & 300 & 300 & 300 & 300 & 300 & 3000 \\
\hline & $\begin{array}{l}\text { Reversed Offsets First, } \\
\text { then Positive Offsets }\end{array}$ & & 700 & 200 & 300 & 300 & 300 & 300 & 300 & 300 & 300 & 3000 \\
\hline & $\begin{array}{l}\text { Positive Offsets First, } \\
\text { then Reversed Offsets }\end{array}$ & 300 & 700 & & 200 & 300 & 300 & 300 & 300 & 300 & 300 & 3000 \\
\hline
\end{tabular}

Table 1. Results of Forecast and Customers' Orders Applying Different Offset Rules

\subsubsection{Net Product Demand Planning}

Net product demand planning is based on the product demand planning, putting the future inventory and safety inventory into considerations and then come to the product net demand planning. Net product demand planning can be derived from the following formula:

$N D_{i}=\max \left(G D_{i}-G S_{i}+S S_{i}, 0\right)$

$N D_{i}$ : Net Product Demand in No. $\mathrm{i}$

$\mathrm{GS}_{\mathrm{i}}$ : Inventory in No. i

$\mathrm{SS}_{\mathrm{i}}$ : Product Safety Stocks in No. i(Safety Stocks are constant in general, but also can be set as variables in accordance with the market fluctuations)

The net product planning will clear and define the future product requirements, and is one of the important basis to make production planning for enterprise.

\subsubsection{Available Capacity Planning}

Available capacity planning is the planning for the available capacity based on the changes between current capacity and forecast capacity. In this model,. Since the assumption product uses single resource, the available capacity planning can be indicated by the product quantity, which is the key of this model. Available capacity planning includes the available capacity under both regular production situation and overtime production, and the overtime production can be expressed in the following formula.

$\mathrm{TQ}_{\mathrm{i}}=\mathrm{NQ}_{\mathrm{i}}+\mathrm{UQ}_{\mathrm{i}}$

$\mathrm{TQ}_{\mathrm{i}}$ : available production capacity in No. i

$\mathrm{NQ}_{\mathrm{i}}$ : product quantity that can be produced under regular production conditions in No. $\mathrm{i}$

$\mathrm{UQ}_{\mathrm{i}}$ : product quantity that can be produced under overtime production conditions in No. $\mathrm{i}$ 
When the regular production capacity allows, overtime production is not recommended due to the problems associated with overtime expenses, employees' emotion, and quality problems etc.

\subsubsection{Multi-Objective Product Production Planning}

Product production planning is the product yield planning in certain period in the future and making production planning shall not only consider the net demand planning and available capacity planning, but also all kinds of performance objectives in the production process comprehensively. Four objectives including in time delivery, production equilibrium, inventory and overtime production, are considered in this model.

\subsubsection{In-time Delivery}

In time delivery refers to deliver product to customers, which meet the quantity and quality in the required date and in time delivery will increase the reputation and customer's satisfaction. However, in realistic conditions, the delayed delivery is irrevocable due to the production capacity, bad equipments, material shortage and other occasional accident or emergency. If the produced product quantity can not meet the net demand, it must be made up in the subsequent production process. The goal of enterprise is to minimize the delayed delivery and by setting the penalty cost in this model can help achieve this goal.

The delayed product amount can be get by calculating the net demand and production planning quantity. Where $Q_{i}$ is the production planning quantity in No. I and $L_{i}$ is the delayed product amount in No. I, then

$$
\mathrm{LQ}_{\mathrm{i}}=\max \left\{\sum_{j=1}^{i}\left(\mathrm{ND}_{\mathrm{j}}-\mathrm{Q}_{\mathrm{j}}\right), 0\right\}
$$

Where $L$ is the penalty cost per delayed product in some time period and LC is the total penalty cost for delayed deliveries, then

$$
L C=\sum_{i=1}^{n}\left(\mathrm{LQ}_{\mathrm{i}} * L\right)
$$

In order to assure the in-time delivery, the smaller LC the better and when LC equals to 0 , then it means that all products can be delivered in time during the planning period. 


\subsubsection{Production Equilibrium}

Production equilibrium refers to the stability and balance of the produced products during each production period of enterprises, which can make the production process easier to control and manage, and guarantee the product quality stability effectively. In this model, production equilibrium is represented by $\mathrm{S}$, which is the standard deviation of the product quantity in each period. The smaller $\mathrm{S}$ becomes, the more balanced the production can be. Otherwise represent the more wide fluctuation of the product quantity produced.

Where $\mathrm{S}$ is the standard deviation of the product quantity in each period, then

$$
\mathrm{S}=\sqrt{\frac{\sum_{i=1}^{n}(Q i-\bar{Q})^{2}}{n-1}} \text {, in which } \bar{Q}=\frac{\left(\sum_{i=1}^{n} Q_{i}\right)}{n}
$$

Where $\mathrm{J}$ is the cost coefficient caused by unbalanced production, and JC stands for total cost of unbalanced production, then

$$
\mathrm{JC}=\mathrm{S}^{*} \mathrm{~J}
$$

\subsubsection{Occupied Inventory}

When the product demand fluctuates widely or inconstantly, temporary buffer inventory may occur to satisfy the customer's needs. Buffer inventory can be regarded as an up-front investment to satisfy the customer's needs and this inventory will bring certain occupied funds, so for cost reasons, this inventory shall be as smaller as possible.

Where $\mathrm{KQ}_{\mathrm{i}}$ is the inventory in No. $\mathrm{i}$, then

$$
\mathrm{KQ}_{\mathrm{i}}=\max \left\{\sum_{j=1}^{i}\left(\mathrm{Q}_{\mathrm{j}}-\mathrm{ND}_{\mathrm{j}}\right), 0\right\}
$$

Where $\mathrm{K}$ is the inventory cost per unit time per unit product, and $\mathrm{KC}$ is the total inventory cost, then

$$
K C=\sum_{i=1}^{n}\left(\mathrm{KQ}_{\mathrm{i}}^{*} K\right)
$$

The inventory cost is supposed to be the less the better, when meeting the customers' needs. 


\subsubsection{Overtime Expenses}

When the regular capacity can not meet the customers' needs effectively, over time work associated with extra overtime cost, will be needed.

Where $A Q_{i}$ stands for the product quantity of overtime production, then

$$
A Q_{i}=\max \left\{Q_{i}-N Q_{i}, 0\right\}
$$

Where A stands for the extra cost per unit product under overtime production, and AC stands for the total overtime cost, then

$$
A C=\sum_{i=1}^{n}\left(\mathrm{AQ}_{\mathrm{i}}^{*} A\right)
$$

The overtime capacity shall be avoid, when the regular capacity can meet the market demand.

\subsection{Optimization Model}

Based on the above mentioned analysis, performance objectives including in time delivery, production equilibrium, inventory and overtime production shall be considered thoroughly, in addition to the net product demand and capacity. All these objectives are interdependent and restrict with each other, which may be hard to reach unify. For example, when the net product demand fluctuates widely, choices between inventory and overtime production shall be made to assure the in time product supply. In order to deal with the fluctuation, there are solutions including increasing the inventory or provide overtime production.

By setting the parameters of the four goals of cost, this model convert the multi-objective optimization problem into a single objective optimization problem (i.e. the minimum total cost), by adjusting the value of the different cost parameters, managers can make a conscious choice of key targets, in order to achieve optimization of the manufacturing process management and control. The model is described as follows.

Objective Coefficient: $T C=\min (L C+J C+K C+A C)$

Decision Variable: $Q_{i}$

Known Data: $\mathrm{FN}_{\mathrm{i}}, \mathrm{ON}_{\mathrm{i}}, \mathrm{GS}_{\mathrm{i}}, \mathrm{SS}_{\mathrm{i}}, \mathrm{UQ}_{\mathrm{i}}, \mathrm{NQ}_{\mathrm{i}}, \mathrm{L}, \mathrm{J}, \mathrm{K}, \mathrm{A}$

Constraints:

- $\quad 0 \ll Q_{i} \ll N Q_{i}+U Q_{i}$ 
The daily production amount cannot excess the sum of regular production capacity and overtime production capacity.

$$
\sum_{i=1}^{n} \mathrm{Q}_{\mathrm{i}}=\sum_{i=1}^{n} \mathrm{ND}_{\mathrm{i}}
$$

Total product quantity shall equal to the sum of net product demands.

- Refer to 2.1.4 for other constraints (1)-(8).

\subsection{Applicable Scope and Solution}

To apply this model, the assumptions in 2 shall be met. Generally speaking, the solution provided by this model is more applicable for medium-and-small-size enterprise or branches, as spare parts supporting manufacturers for large-scale enterprise, and this solution can also be applied to planning and control to manufacture spare parts and products in production for enterprise's key resources. To solve this model, the most used software such as SPSS or MATLAB can be applied. About the software, it is unnecessary to go into details here.

\section{Case Analysis and Implementation}

\subsection{Case Analysis}

The enterprise production demand and production capacity is as in Table 2 . We will analyze by applying two different performance and objective management combinations.

(1) Consider in-time delivery and inventory according to priority

To reflect the priority order, expense parameters, including $L=100, K=1, J=0, A=0$, are set to carry out the optimization model and the results are shown in Table 2.

\begin{tabular}{|c|c|c|c|c|c|c|c|c|c|c|c|c|c|c|}
\hline & & 1 & 2 & 3 & 4 & 5 & 6 & 7 & 8 & 9 & 10 & 11 & 12 & Total \\
\hline \multirow{3}{*}{ Demand } & Forecast (after average) & 150 & 150 & 150 & 150 & 150 & 150 & 250 & 250 & 250 & 250 & 250 & 250 & 2400 \\
\hline & $\begin{array}{l}\text { Orders(Reversed } \\
\text { Cancellation) }\end{array}$ & & & 200 & & & & & 380 & & & & & 580 \\
\hline & Net Demand & 150 & 100 & 200 & 150 & 150 & 150 & 120 & 380 & 250 & 250 & 250 & 250 & 2400 \\
\hline \multirow{3}{*}{ Capacity } & Regular Capacity & 200 & 200 & 200 & 200 & 200 & 200 & 100 & 100 & 200 & 200 & 200 & 200 & 2200 \\
\hline & Over-time Capacity & 150 & 150 & 150 & 150 & 150 & 150 & 0 & 0 & 150 & 150 & 150 & 150 & 1500 \\
\hline & Total Capacity & 350 & 350 & 350 & 350 & 350 & 350 & 100 & 100 & 350 & 350 & 350 & 350 & 3700 \\
\hline \multirow{4}{*}{ Planning } & Production Planning & 150 & 100 & 200 & 150 & 250 & 350 & 100 & 100 & 250 & 250 & 250 & 250 & 2400 \\
\hline & Inventory Planning & & & & & 100 & 300 & 280 & & & & & & 680 \\
\hline & Overtime Planning & & & & & 50 & 150 & & & 50 & 50 & 50 & 50 & 400 \\
\hline & Delayed Delivery Planning & & & & & & & & & & & & & \\
\hline
\end{tabular}

Table 2. Optimization Process of Considering On-time Delivery and Product Inventory 
As shown in Table 2, all products can be delivered in time with no delays. The total quantity of product inventory is 680, separated in time zones No. 5, 6 and 7. The inventory is resulted in the product net demand surplus the production capacity (including the overtime capacity) in time zone No. 8, so that enterprise shall produce in advance to make sure deliver the product in time in time zone No. 8 . The total overtime production quantity of the enterprise is 400 , distributed in 6 time zones which are No. 5, 6, 9, 10, 11, and 12.

\section{(2) Consider In-time delivery, overtime expenses and inventory according to priority}

Set parameters, where $L=10000 、 A=100, J=0, K=1$, execute the optimization model and get the results shown as in Table 3.

\begin{tabular}{|c|c|c|c|c|c|c|c|c|c|c|c|c|c|c|}
\hline & & 1 & 2 & 3 & 4 & 5 & 6 & 7 & 8 & 9 & 10 & 11 & 12 & Total \\
\hline \multirow{3}{*}{ Demand } & $\begin{array}{l}\text { Forecast } \\
\text { (after average) }\end{array}$ & 150 & 150 & 150 & 150 & 150 & 150 & 250 & 250 & 250 & 250 & 250 & 250 & 2400 \\
\hline & $\begin{array}{l}\text { Orders(Reversed } \\
\text { Cancellation) }\end{array}$ & & & 200 & & & & & 380 & & & & & 580 \\
\hline & Net Demand & 150 & 100 & 200 & 150 & 150 & 150 & 120 & 380 & 250 & 250 & 250 & 250 & 2400 \\
\hline \multirow{3}{*}{ Capacity } & Regular Capacity & 200 & 200 & 200 & 200 & 200 & 200 & 100 & 100 & 200 & 200 & 200 & 200 & 2200 \\
\hline & Over-time Capacity & 150 & 150 & 150 & 150 & 150 & 150 & 0 & 0 & 150 & 150 & 150 & 150 & 1500 \\
\hline & Total Capacity & 350 & 350 & 350 & 350 & 350 & 350 & 100 & 100 & 350 & 350 & 350 & 350 & 3700 \\
\hline \multirow{4}{*}{ Planning } & Production Planning & 200 & 200 & 200 & 200 & 200 & 200 & 100 & 100 & 250 & 250 & 250 & 250 & 2400 \\
\hline & Inventory Planning & 50 & 150 & 150 & 200 & 250 & 300 & 280 & & & & & & 1380 \\
\hline & Overtime Planning & & & & & & & & & 50 & 50 & 50 & 50 & 200 \\
\hline & Delayed Delivery Planning & & & & & & & & & & & & & \\
\hline
\end{tabular}

Table 3. Optimization Process considering In-time Delivery, Overtime Expenses and Inventory

From Table 3, it can tell that all products will be delivered in time and no delay will happen. The total overtime production quantity is 200 , distributed in time zones no. 9 to no.12, because that the regular capacity cannot satisfy the net product demand, and overtime production is necessary. Compared with Table 2, the overtime yield drops from 400 to 200, but he inventory increases to 1380 , which is much more than the inventory of 680 listed in Table 2.

The same reason for other objective combination and it is unnecessary to go into details here. Through the above analysis, it can be found that every objective influencing the production process often restricts with each other and the managers of enterprise can focus on different management objectives by setting corresponding parameters and cost parameters can certainly be determined according to the actual situation and decisions can be made by putting all the objectives together.

\subsection{Implementation}

Based on the above mentioned model, we develop a multi-objective production planning and optimization system, which has been applied in a company producing special matching parts for liquid crystal display. This company produces and provides same spare parts for many LCD 
manufacturers and the production planning is influenced by the upstream manufacturers and for this reason the production is of relatively wide fluctuations. When enterprise make production planning, strict requirements shall be followed by the upstream manufacturers, while considering some other management objectives of itself. In the field research, it has been found that the inventory of this company has remained high due to the wide fluctuation of the product demand and overtime productions have occurred and the order fulfillment rate has been around $85 \%$. So far, enterprise pays most attention on the key objectives, including product delivery time, product inventory and overtime production (according to the priority). In accordance with the actual situation, optimization software we developed has been applied in production planning and control process, which solve the multiple management objectives in the production progress better and the application effects are as shown in Table 4.

\begin{tabular}{|c|l|}
\hline $\begin{array}{c}\text { Production Planning } \\
\text { and Control }\end{array}$ & \multicolumn{1}{c|}{ Application Effect of the Optimization System } \\
\hline $\begin{array}{c}\text { Production Demand } \\
\text { Management }\end{array}$ & $\begin{array}{l}\text { Make the Net Product Demand Planning quickly according to the average and offset } \\
\text { rules }\end{array}$ \\
\hline Make Production Planning & Set Objective coefficient, and get the optimized production planning automatically \\
\hline $\begin{array}{c}\text { Availability of Capacity } \\
\text { Planning }\end{array}$ & $\begin{array}{l}\text { Put capacity into consideration when making the production planning and the } \\
\text { production capacity is completely feasible. }\end{array}$ \\
\hline In-time Delivery & In-time delivery rate reaches more than $95 \%$ which is $10 \%$ higher than before. \\
\hline Inventory & Inventory drops $11 \%$ on average. \\
\hline Overtime Production & Overtime work has been cut on certain level. \\
\hline
\end{tabular}

Table 4. Application Effects

\section{Conclusions}

As the most important function, production planning and control has crucial impact on the smooth progress of the production and business activities and cost control of enterprise. This paper briefly analyzes the construction and disadvantages of ERP system and proposes an optimization model based on multi-objective production planning. The optimized objectives are in-time delivery, balanced production, inventory, overtime production and other management objectives in the production progress and through setting cost parameters for all kinds of production objectives in order to maintain the balances among multiple objectives. Case analysis and detailed applications are given in this paper and the results show that the optimization solution proposed by this model can give decisive supports to the production planning for manufacturing industry and increase the feasibility and effectiveness of production planning.

The model built up in this paper is relatively simply and only applied in manufacturing enterprise with single resource and single bill of material. The future studies will be expanded into multiple occupied resources, multi-level bill of materials, and more production management objectives to enhance the applications of this model. 


\section{Acknowledgment}

This research work was sponsored by youth academic backbone support program of Heilongjiang Province (1251G071), and Science and technology project of Heilongjiang Province (GZ12D508), and young teachers scientific research support program of Qiqihar University (2011k-z10).

\section{References}

Chen, Z. (2001). Flexible decision of MPS in MRP II system. Journal of Systems Engineering, $06,465-470$.

Cui, N., Liu, Y., \& Yan, S. (2003). Improvement of lead time in MRP. Journal of Huazhong University of Science and Technology, 5, 95-97.

Hao, G., \& Wu, G. (2005). Research on MRP of dynamic lot size \& lead-time based on daily output. The computer integrated the manufacturing system, 09, 1267-1271.

Hao, Y. (2008). Research on the Production Scheduling Optimization Methods for Tobacco Enterprises. Huazhong University of Science and Technology.

Huang, W., Cai, L., Hu, Y., Wang, X., \& Ling L., (2009). Process planning optimization based on genetic algorithm and topological sort algorithm for digraph. Computer Integrated Manufacturing Systems, 9, 1770-1778.

Jia, W., Liao, X., Wang, M., \& Shen, Z. (2002). Aggregate Production Planning with MultiObjectives in Uncertain Environment. Systems engineering, 05, 50-54.

Jodlbauer, H., \& Reitner, S. (2012). Material and capacity requirements planning with dynamic lead times. International Journal of Production Research , 50(16), 4477-4492. http://dx.doi.org/10.1080/00207543.2011.603707

Kanet, J.J., \& Stlein, M. (2010). Integrating production planning and control: towards a simple model for Capacitated ERP. Production Planning \& Control, 21(3), 286-300. http://dx.doi.org/10.1080/09537280903363209

Kopanos, G.M., Puigjaner, L. \& Georgiadis, M.C. (2010). Optimal Production Scheduling and Lot-Sizing in Dairy Plants: The Yogurt Production Line. Industrial and Engineering Chemistry Research, 49(2), 710-718. http://dx.doi.org/10.1021/ie901013k

Kopanos, G.M., Puigjaner, L. \& Georgiadis, M.C. (2011). Production Scheduling in Multiproduct Multistage Semicontinuous Food Processes. Industrial \& Engineering Chemistry Research, 50(10), 6316-6324. http://dx.doi.org/10.1021/ie2001617

Lan, B. (2004). Enterprise Resource Optimization and Optimization Model. Computer Integrated Manufacturing Systems, 3, 241-250. 
Liu, W., Wang, T., Zhou, M., \& Rao, J. (2010). Generation and optimization of process routing based on ant colony algorithm. Computer Integrated Manufacturing Systems, 7, 1378-1382.

Liu, B., Zhou, Y., \& Liu, B. (2001). MRPII Principles and Implementation. Tianjin: Tianjin University Press.

Pan, E., Liao, W., \& Xi, L. (2010). Single-machine-based production scheduling model integrated preventive maintenance planning. The International Journal of Advanced Manufacturing Technology, 50(1-4), 365-375. http://dx.doi.org/10.1007/s00170-009-2514-9

Shu, C., \& Wang, D. (2010). An Improved Genetic Algorithm for Partial Flexible Job-Shop Scheduling. Industrial Engineering, 6, 61-65.

Smith, N.R., Robles, J.L., \& Cárdenas-Barrón L.E. (2009). Optimal Pricing and Production Master Planning in a Multiperiod Horizon Considering Capacity and Inventory Constraints. Mathematical Problems in Engineering: Theory, Methods and Applications, 2009, 1-15.

Wang, C., Liu, X., Lin, Y., \& Zhao, G. (2012). Production scheduling model based on the finite capacity of discrete manufacturers. Science-technology and management, 05, 99-102.

Wang, D., Zhang, H., \& Lu, J. (2007). Research and Application of APS Algorithm based on the Bottleneck Restriction. Mechatronics, 6, 35-39.

Witkowski, T., Antchak, A., \& Antchak, P. (2004). The CSANN Neural Model Modification for Production Scheduling. Journal of Automation and Information Sciences, 36(9-10), a44-a50. http://dx.doi.org/10.1615/JAutomatInfScien.v36.i10.50

Xiao, Y., Zhang, R., \& Chang, W. (2010). Enterprise planning model based on bill of manufacturing. System Engineering Theory and Practice, 2, 227-235.

Zhang, Q., \& Wang, J. (2008). The Research on Integrated Production Planning and Controlling Method of Customer-centered Production. Journal of Industrial Engineering and Engineering Management, 22(1), 151-154.

Zhuang, Y., \& He, J. (2002). An Improved Capacity Requirements Planning Method for MRP II /ERP Systems. Management Science of China, 5, 62-68. 